\title{
Study of the Development of Piano Teaching under Multi-cultural Background
}

\author{
Yun Kailing \\ Yunnan Normal University, Kunming, Yunnan, China
}

Keywords: diversification; piano teaching; culture

\begin{abstract}
With the rising trend of cultural globalization, the diversity of social culture is becoming increasingly obvious. Especially, as a foreign musical instrument, piano has naturally obtained its intrinsic multiple characteristics in the process of interweaving and integrating with the native musical culture, which means that in the process of piano teaching, based on the social cultural overall background and the peculiarity of piano music, a multicultural perspective should be taken in order to promote the cultivation of diversified piano talents, thus meeting the actual needs of the society. Based on the multicultural background, the paper puts forward comprehensive development strategies based on a brief analysis of the existing problems in present piano teaching, which has certain reference value.

With the advent of the globalization age and the increasingly frequent international cultural exchanges, the development of multi-culture has become a dominant trend, which definitely involves every side of musical culture. As a mainstream musical instrument in nowadays society, piano's abundant functions and broad audiences determine the importance of piano talents training, and piano teaching is a key link of piano talents training, so carrying out piano teaching based on the multicultural background is not only the need of the times but also the need of the society.
\end{abstract}

\section{Problems in Piano Teaching}

\subsection{Problems in teaching staff}

The construction of teaching staff is one of the indispensable factors in piano teaching. At present, defects exist in both quality and quantity of the piano teaching staff. Except for external teachers and part-time teachers, the number of in-service piano teachers is relatively small, which can not meet the needs of teaching status. In terms of the quality of teachers, the teachers are mostly undergraduates and graduate students, and teachers with a doctoral degree are lacking. Therefore, the piano teachers are defective in terms of quality. In addition, although the teachers' comprehensive abilities have improved, in order to keep pace with the times, piano teachers are required to continuously improve their comprehensive abilities and attainment, and to form novel and unique ideas in the course of teaching, thereby avoiding hidebound teaching.

\subsection{Problems in teaching mode}

At present, the piano teaching mode is relatively conventional and simplex, and mainly based on individual teaching and group teaching. The teaching course is mainly based on teachers' demonstration and students' imitation, which is conductive to teachers' adopting targeted teaching on students and finding and timely correcting problems. But deficiency also exists, namely, the students' self-creation and thinking abilities are neglected, and they are simply in the passive state of imitating the teachers, which is adverse to the development of piano teaching.

\subsection{Problems in students' abilities}

Generally speaking, the students already possess certain piano performance level when entering school. But most of the students merely exercise the exam programs in order to deal with the art exam before admission to the school. As a result, the students have varied performance levels and only pay attention to the proficiency of the programs, while ignoring the analysis of musical works and emotional expression. The actual piano performance level of some students is different from 
that displayed in the exam programs they played, which will exert a negative impact on their further study. Hence, teachers should realize the difference in teaching and strive to reduce and eliminate the difference one by one.

\subsection{Problems in course setup}

At present, piano teaching has some defects in course setup. Firstly, in terms of the course arrangement of music performance specialty, in addition to piano tutorial, the courses of the music performance specialty also include Double Piano Performance, Arts Guide of Chamber Music, Piano Art History (for postgraduate stage) and Piano Teaching Method. Disciplines regarding piano theories, such as Piano Teaching Method and History of Piano Art, are only available in one term, which shows that these disciplines are not attached enough importance to, thus highlighting that the piano teaching stresses more on skills while making light of music, and ignores the aesthetic perception of music in the piano teaching. Secondly, in terms of the course arrangement of music education specialty, the training objects are music teachers in middle and primary schools, and they play an important role in both teaching and learning. But the course setup did not pay enough attention to courses such as Psychology, Pedagogy and Music Teaching Method, and set them as elective courses, resulting in that the students take no account of these courses, and did not realize the importance of these courses for their future teaching. In general, in the context of multi-culture, the course setup is to cultivate multiple-ability talents needed by the society. The problems in the above courses will negatively affect the development of piano teaching, so the course setup still needs to be adjusted.

\subsection{Problems in piano musical selection}

At present, most of the piano works played by students in school period are those created in the classical era, the Baroque era and the romantic era, thereinto, works created in the classical era are the most. Few of the works played were created in the impressionism era or belong to Chinese national piano works. Thus it can be seen that most of the piano works chosen by the teachers are foreign piano works, and few outstanding Chinese piano works have been selected, which is adverse to the transmission of diversified piano culture to students in the course of teaching, lead to that the students know little about the national piano works and historic culture, and is not conductive to the transmission of outstanding Chinese piano culture to the students.

\section{Development Strategies for Piano Teaching under Multicultural Background}

\subsection{Gradual strengthening of teacher resource}

The teaching process of piano consists of two parts of "teaching" and "learning", and the two parts can not be separated from each other. In the course of teaching, the role of teaching is often played by piano teachers, and the role of learning is acted by students. An excellent piano teacher should penetrate the teaching idea of cultivation of people throughout the whole teaching process, they should not only teach students how to play the piano and practice playing the piano, but also teach students how to timely summarize their shortcomings in study and analyze the reasons of the problems. Only in this way will the students who rely on teachers be gradually transformed to those able to learn independently. Thus, piano teachers always play a leading role in the course of teaching. Therefore, it is the first step strengthening the ability of piano teachers in the present piano teaching.

\subsubsection{Improvement of teachers' comprehensive quality}

First, the theoretical knowledge of piano teachers should be reinforced. Piano teaching is a course requiring solid foundation, and has its own characteristics and rules. In terms of teaching ability, piano teachers in the 21st century should possess solid theoretical knowledge, so that they can well apply their diversified horizon to analyze and study novel piano teaching ideas in China and abroad, broaden their horizon, and apply theoretical knowledge to their practical teaching, thus enriching the theoretical knowledge reserve of the students. The theoretical knowledge of piano 
teaching has also been gradually accumulated with the continuous enrichment of piano works, the constant improvement of piano performance skills and the historical development of piano music. Therefore, the theoretical knowledge of piano teaching plays an important role in the future teaching development.

Second, the skill level of piano teachers should be enhanced. In the process of piano playing and teaching, skill level affects the teachers' performance of music works. Not only piano skills, namely, the ability of piano playing, but also the teaching ability of teachers in the teaching process will directly affect the learning effect of students. Therefore, in the teaching link, teachers should possess the ability to perform individualized teaching, the ability to organize teaching, the ability to express language, and the ability to timely grasp the students' psychological dynamics. In addition, the knowledge structure of teachers should include cultural knowledge literacy, as the mastery of profound cultural and historical knowledge and the expansion of teachers' thinking space are of significant significance for the expected result of piano teaching.

\subsubsection{Employment of Chinese and foreign piano experts}

In terms of the allocation of teacher resource, the current faculty structure is relatively weak. More attention should be paid to the proportional allocation of teachers, more Chinese and foreign piano experts should be employed to conduct exchanges and interviews with piano teachers and students in the department of music, piano special concerts, academic seminars and courses for viewing and emulating should be organized to broaden the knowledge vision and improve the comprehensive ability of the teachers and students. Meanwhile, teaching experts can be employed jointly with other higher schools to carry out education in coalition.

\subsection{Reasonable construction of teaching materials}

The selection of teaching materials is an indispensable link in the teaching process, as well as the basic guarantee for piano teaching. At the primary stage of teaching, teachers will select suitable piano works for students according to the students' comprehensive abilities and performance ability, which is a great challenge for on-the-job piano teachers. Whether a piano teacher is able to correctly and reasonably choose textbooks is also a standard for judging whether the teacher is excellent or not in nowadays society. So far, there is no accurate standard for judging whether the selection of textbooks is correct or not. It is indeed difficult for piano teachers to make reasonable choice and collocation with the countless piano works, yet there is still rule to follow. First of all, before choosing the work, piano teachers should have enough understanding of the students' performance level, and deeply study or analyze which programs are suitable for the students, and make targeted choices for the students. Besides, the teachers can apply some of the elements of national music into piano works, thus they can transmit native music culture as well as music aesthetic emotions while training the students' piano playing skills. This is also one of the important tasks that piano teachers should fulfill to inherit the diversified national music of Sinkiang. Secondly, piano works of different genres should be mutually collocated, piano works of different styles should be mutually permeated, the scope of musical selection should be widened, the works selected should be no longer limited to those of the classical era, and neoteric and modern works and Chinese piano works can be integrated into teaching. Furthermore, in the selection of teaching materials, teachers should strive to achieve "Integrated Chinese and Western", start from the perspective of diversified music education, choose targeted piano works suitable for the students, and abandon wholesale westernized teaching and teaching materials. Finally, piano teachers can make a bold trial of compiling and creating distinctive teaching materials in the future textbook compilation, so as to enhance the students' recognition of national music, enrich the piano teaching content, and make it be constantly innovated in the process of development.

\subsection{Scientific course setup}

Course setup and optimizing reform is one of the important means in piano teaching. Optimizing piano courses is also a method to enrich the diversity of piano teaching. The mutual integration, complementation and supplementary between disciplines has certain promoting effect in course 
setup. The author thinks that a courses teaching system should be advocated in the course of piano teaching, with the system the students' actual performance ability can be quickly improved through the study of piano specialized courses, the students' theoretical knowledge reserve ability can be enhanced through the study of theoretical courses such as Piano Teaching Method and History of Piano Art, through the setting of elective courses such as psychology and education, and the students' personal cultural attainment can be enhanced through the setup of elective courses such as Psychology and Pedagogy. The establishment of such course system can broaden the cultural horizon and improve the practical ability of the students, and lay a solid foundation for the students in future work.

\subsection{Diversified application of teaching modes}

In the process of teaching, because of the different teaching contents and methods, the application of teaching mode and the value reflected are also different. The main teaching modes include demonstration and imitation mode, transmission and acceptance mode, self-study guidance mode, participation and experience mode, situation cultivation mode, exploration and creation mode, behavioral mutual assistance mode, guided discovery mode and cooperative mutual assistance mode. Under the edification and influence of multi-culture, simplex and traditional teaching mode cannot be fully competent in today's society and is not a long-term policy in piano teaching. As far as the teaching mode adopted in current piano teaching is concerned, demonstration and imitation mode and transmission and acceptance mode are the most widely used, from which it can be seen that the current teaching modes can no longer meet the requirements of the present situation. Therefore, starting from the practice of piano teaching, the author thinks that based on the original teaching mode, diversified application of multiple teaching modes such as self-study guidance mode, participation and experience mode and cooperative mutual assistance mode should be carried out to meet the needs of diversified talents training.

\subsection{Integral improvement of students' abilities}

Nowadays, with the rapid development of social economy, music education is also constantly moving forward in the development of diversified educational enterprise, and new level and requirements have been raised for the training of piano talents. The career development after graduation of the students has triggered a lot of thoughts in the author. The traditional personnel cultivating program can no longer meet the needs of modern society. Hence, in the course of piano teaching, skill-oriented knowledge should be permeated into diversified music learning, so that the students can quickly master occupational skills and convert their original student status to the role of teacher or performance talent, thus enabling the students to fully embody the application value in the society.

\section{References}

[1] Zhang Xuan. Piano teaching reform in Chinese higher schools from the viewpoint of multiculture [J]. Musical Composition, 2017, (8);

[2] Wang Xiaokun. Study of piano teaching reform in normal universities under the background of multicultural education [J]. Journal of Henan Normal University (Philosophy and Social Science Edition), 2010, (9).

[3] Qi Li. The application of diversified teaching mode in piano teaching [J]. China Adult Education, 2008, (7). 